\title{
A Population-based Prospective Study on Obesity- related Non-communicable Diseases in Northern Iran
}

\section{Nima Motamed}

Zanjan University of Medical Sciences

Farhad Zamani ( $\boldsymbol{D}$ zamani.f@iums.ac.ir)

Iran University of Medical Sciences

Mansooreh Maadi

Iran University of Medical Sciences

Hossein Ajdarkosh

Iran University of Medical Sciences

Farzin Roozafzai

Iran University of Medical Sciences

Hossein Keyvani

Iran University of Medical Sciences

Hossein Poustchi

Tehran University of Medical Sciences

Ramin Shakeri

Tehran University of Medical Sciences

G. Hossein Ashrafi

Kingston University

Dhayaneethie Perumal

Kingston University

Behnam Rabiee

Montefiore Medical Center

Maziar Moradi-Lakeh

Iran University of Medical Sciences

Mahmoodreza Khoonsari

Iran University of Medical Sciences

Mitra Ameli

Iran University of Medical Sciences

Mehdi Nikkhah

Iran University of Medical Sciences

Amir Hossein Faraji 
Iran University of Medical Sciences

\section{Zahedin Kheyri}

Arak University of Medical Sciences

Masoud Reza Sohrabi

Iran University of Medical Sciences

\section{Bahare Amirkalali}

Iran University of Medical Sciences

\section{Fahimeh Safarnezhad Tameshkel}

Iran University of Medical Sciences

\section{Esmaeel Gholizadeh}

Iran University of Medical Sciences

\section{Seyed Hamzeh Hosseini}

Mazandaran University of Medical Sciences

Mohammad Hadi Karbalaie Niya

Iran University of Medical Sciences

\section{Research Article}

Keywords: Cardiovascular disease, Cohort study, Metabolic disorder, Obesity, Risk assessment

Posted Date: February 2nd, 2022

DOI: https://doi.org/10.21203/rs.3.rs-1266308/v1

License: () (1) This work is licensed under a Creative Commons Attribution 4.0 International License. Read Full License 


\section{Abstract}

We conducted a population-based prospective study to assess prevalence and incidence rates of cardiovascular diseases (CVDs) and obesity-related metabolic disorders, and to evaluate predictive ability of various CVD risk assessment tools, in a population not represented in existing CVD cohorts. We enrolled 5,799 participants in Amol, a city in northern Iran, in 2009-2010, and carried out first repeated measurement (RM) after seven years (2016-2017). For all participants, demographic, anthropometric, laboratory, hepatobiliary imaging, and electrocardiography data have been collected in the enrollment and the first RM. At least two more RM phases, with 7-year intervals, are considered for a comprehensive evaluation of participants (commencing in 2023 and 2030). After enrollment, all participants have been and will be followed up annually for 20 years, both actively and passively. We adopted a multidisciplinary approach to overcome barriers to participation, and achieved a 7-year follow-up success rate of $93.0 \%$ with active follow-up of 5,394 participants aged 18-90 years. Of 160 deceased participants, 69 cases (43.1\%) died due to CVDs during seven years. The study outcomes offer an evidence base for future researches, and inform policies regarding non-communicable diseases in Iran.

\section{Introduction}

The global prevalence of chronic non-communicable diseases (NCDs) is rising [1, 2]. NCDs are the primary cause of both morbidity and mortality [1, 2]. According to the World Health Organization, by 2030, NCDs will account for $80 \%$ of mortalities worldwide [2]. Iran, a low- and middle-income country (LMIC), is facing an epidemiological transition with increasing burden of NCDs [3].

Trends in obesity and obesity-related metabolic disorders, such as non-alcoholic fatty liver disease (NAFLD), type 2 diabetes mellitus (T2DM), and metabolic syndrome (MetS), are rising worldwide, and particularly in Iran, due to inappropriate lifestyle, such as physical inactivity, and high-calorie diets [4]. Studies showed a critically increased prevalence of obesity in adults and children during previous decades such that 2.1 billion individuals were identified as overweight or obese [5]. Exacerbation of anthropometric characteristics of a population might contribute to an increase in mortality and morbidity rates in that population. Studies observed that for every 5-unit increase in the body mass index (BMI) above $25 \mathrm{~kg} / \mathrm{m}^{2}$, the mortality rate increased by $29 \%[6,7]$. The increasing prevalence of obesity, as well as T2DM, also associates with the rising trend of NAFLD, an emerging healthcare challenge in Asia which is prevalent in about a third of Iranian adults [8-11].

Meanwhile, cardiovascular diseases (CVDs) and their associated risk factors are major burdens for global health $[12,13]$. Causing $46 \%$ of global mortality, CVDs are the leading cause of death worldwide $[2,12$, 13]. Approximately, $42 \%$ of NCD-related premature deaths are attributed to CVDs [2]. Following the global trends, Iran is experiencing high burdens of CVDs accounting for $51 \%$ of deaths in the country $[2,14-16]$. Unlike LMICs, high-income countries have decreased CVD-related mortality rates through effective preventive approaches and robust therapeutic interventions during recent years [17]. 
Although a close relationship was ascertained between metabolic disorders, CVDs, and NAFLD [18-21], large community-based longitudinal studies can provide comprehensive data for assessment of demographical, epidemiological, and molecular determinants of these major burdens of diseases [3, 22]. This in turn can affect efficiency of public health systems, development and implementation of community-tailored predictive tools, informing of policy, and adoption of new public health initiatives for improving socioeconomic determinants of health and alleviating their impact on NCD mortality and morbidity [3, 22].

Therefore, we designed and launched a population-based prospective longitudinal study, named Amol Cohort Study (AmolCS), in 2009 with the primary aim of determining the incidence rates and risk factors of NAFLD, metabolic diseases, and CVDs in northern Iran, and evaluating the predictive validity of CVD risk assessment tools. We also aimed to develop and validate population-customized risk assessment tools based on the data of an LMIC.

\section{Outcomes of interest}

The outcomes of interest in the AmolCS include: number of cause-specific deaths; incidence of CVDs, metabolic disorders, including MetS and T2DM, liver diseases, including NAFLD (defined by ultrasonographic evidence of hepatic fat accumulation, i.e., markedly increased hepatic echogenicity, and ruling out other causes of hepatitis as well as secondary steatosis due to alcohol, steatogenic medications, or genetic diseases), and viral hepatitis B and C; and trends in major risk factors associated with NCDs, including anthropometric measurements, physical activity, and physiological, lifestyle, nutritional, and environmental factors.

\section{Results}

\section{Cohort attrition}

The 7-year migration rate was not high; only 46 participants $(0.7 \%)$ emigrated from the cohort catchment area. The attrition of the cohort included another 359 participants who withdrew from the study (Fig. 1). A 7-year follow-up success rate of $93.0 \%$ was achieved with active follow-up of 5,394 participants.

\section{Prevalence of diseases}

Some basic findings of the enrollment and the first repeated measurement (RM) are reported in Table 1. In the enrollment phase (2010), $63.9 \%$ of men and $80.9 \%$ of women were overweight or obese (BMI $\geq 25$ $\mathrm{kg} / \mathrm{m}^{2}$ ). In the first RM (2017), $64.0 \%$ of men and $81.2 \%$ of women were overweight or obese. The baseline prevalence rates [95\% confidence interval] of NAFLD grades 2 , and 3 were $9.1 \%$ [7.9-10.2\%], and $1.5 \%[1.0-2.0 \%]$ in men, and $11.1 \%[9.7-12.5 \%]$, and $2.0 \%[1.4-2.6 \%]$ in women, respectively; these rates respectively increased to $16.2 \%$ [14.7-17.7\%], 5.2\% [4.3-6.1\%], 15.6\% [14.0-17.2\%], and 3.0\% [2.0-4.0\%] in the first RM. The baseline prevalence of T2DM was 9.1\% [8.0-10.1\%] in men and $16.4 \%[14.8-17.9 \%]$ 
in women. After seven years, the rates respectively changed to $11.2 \%$ [9.5-12.7\%] and $20.9 \%$ [18.7$23.0 \%]$. 
Table 1

Some basic characteristics of participants in the enrollment (2010) and first repeated measurement (2017) phases of the Amol Cohort Study

\begin{tabular}{|c|c|c|c|c|c|}
\hline \multirow[b]{2}{*}{ Variable } & \multirow[b]{2}{*}{ Categories } & \multicolumn{2}{|l|}{ Enrollment $^{*}$} & \multicolumn{2}{|c|}{ First Repeated Measurement ${ }^{*}$} \\
\hline & & $\begin{array}{l}\text { Men }(n= \\
\text { 3293) }\end{array}$ & $\begin{array}{l}\text { Women }(n= \\
2504)\end{array}$ & $\begin{array}{l}\text { Men }(n= \\
2926)\end{array}$ & $\begin{array}{l}\text { Women }(n= \\
2221)\end{array}$ \\
\hline \multirow[t]{4}{*}{$\mathrm{BMI}^{\mathrm{a}}$} & Underweight & $2.2(1.7-2.8)$ & $1.7(1.1-2.3)$ & $1.3(0.8-1.7)$ & $1.5(0.9-2.1)$ \\
\hline & Normal & $\begin{array}{l}33.9(32.0- \\
35.7)\end{array}$ & $\begin{array}{l}17.4(15.7- \\
19.1)\end{array}$ & $\begin{array}{l}34.6(32.6- \\
36.6)\end{array}$ & $\begin{array}{l}17.3(15.6- \\
19.1)\end{array}$ \\
\hline & Overweight & $\begin{array}{l}40.7(38.8- \\
42.6)\end{array}$ & $\begin{array}{l}31.7(29.6- \\
33.8)\end{array}$ & $\begin{array}{l}42.9(40.9- \\
45.0)\end{array}$ & $\begin{array}{l}35.4(33.2- \\
37.6)\end{array}$ \\
\hline & Obese & $\begin{array}{l}23.2(21.5- \\
24.8)\end{array}$ & $\begin{array}{l}49.2(47.0- \\
51.4)\end{array}$ & $\begin{array}{l}21.1(19.5- \\
22.8)\end{array}$ & $\begin{array}{l}45.8(43.5- \\
48.1)\end{array}$ \\
\hline \multirow[t]{4}{*}{$\begin{array}{l}\text { Total } \\
\text { Cholesterol }{ }^{\mathrm{b}}\end{array}$} & Desirable & $\begin{array}{l}68.7(67.0- \\
70.5)\end{array}$ & $\begin{array}{l}59.9(57.7- \\
62.0)\end{array}$ & $\begin{array}{l}73.7(71.8- \\
75.5)\end{array}$ & $\begin{array}{l}70.9(68.8- \\
73.0)\end{array}$ \\
\hline & $\begin{array}{l}\text { Borderline } \\
\text { high }\end{array}$ & $\begin{array}{l}23.9(22.3- \\
25.6)\end{array}$ & $\begin{array}{l}28.2(26.2- \\
30.2)\end{array}$ & $\begin{array}{l}20.9(19.2- \\
22.6)\end{array}$ & $\begin{array}{l}21.5(19.6- \\
23.4)\end{array}$ \\
\hline & High & $6.7(5.8-7.7)$ & $\begin{array}{l}10.4(9.1- \\
11.8)\end{array}$ & $5.0(4.1-6.0)$ & $6.4(5.3-7.6)$ \\
\hline & Very high & $0.6(0.3-0.9)$ & $1.5(0.9-2.0)$ & $0.4(0.1-0.7)$ & $1.2(0.7-1.7)$ \\
\hline \multirow[t]{6}{*}{ LDL-C ${ }^{c}$} & Very low & $\begin{array}{l}10.4(9.2- \\
11.6)\end{array}$ & $8.1(6.9-9.3)$ & $\begin{array}{l}13.0(11.6- \\
14.4)\end{array}$ & $\begin{array}{l}11.5(10.0- \\
13.0)\end{array}$ \\
\hline & Low & $\begin{array}{l}32.6(30.8- \\
34.4)\end{array}$ & $\begin{array}{l}29.0(27.0- \\
31.0)\end{array}$ & $\begin{array}{l}43.0(40.9- \\
45.0)\end{array}$ & $\begin{array}{l}42.9(40.6- \\
45.2)\end{array}$ \\
\hline & $\begin{array}{l}\text { Borderline } \\
\text { low }\end{array}$ & $\begin{array}{l}35.2(33.4- \\
37.0)\end{array}$ & $\begin{array}{l}36.2(34.1- \\
38.4)\end{array}$ & $\begin{array}{l}33.5(31.6- \\
35.5)\end{array}$ & $\begin{array}{l}33.4(31.3- \\
35.6)\end{array}$ \\
\hline & $\begin{array}{l}\text { Borderline } \\
\text { high }\end{array}$ & $\begin{array}{l}16.9(15.5- \\
18.4)\end{array}$ & $\begin{array}{l}20.4(18.6- \\
22.2)\end{array}$ & $\begin{array}{l}9.3(8.1- \\
10.5)\end{array}$ & $\begin{array}{l}10.4(9.0- \\
11.8)\end{array}$ \\
\hline & High & $3.9(3.2-4.7)$ & $5.0(4.0-5.9)$ & $1.1(0.6-1.5)$ & $1.5(0.9-0.2)$ \\
\hline & Very high & $0.8(4.5-1.2)$ & $1.2(0.7-1.7)$ & $0.1(0.0-0.3)$ & $0.3(0.0-0.5)$ \\
\hline \multirow[t]{2}{*}{ HDL-C d } & Low & $\begin{array}{l}45.9(44.0- \\
47.8)\end{array}$ & $\begin{array}{l}65.1(63.0- \\
67.2)\end{array}$ & $\begin{array}{l}46.2(44.4- \\
48.1)\end{array}$ & $\begin{array}{l}67.0(65.1- \\
69.0)\end{array}$ \\
\hline & Normal & $\begin{array}{l}54.1(52.2- \\
56.0)\end{array}$ & $\begin{array}{l}34.9(32.8- \\
37.0)\end{array}$ & $\begin{array}{l}53.8(51.9- \\
55.6)\end{array}$ & $\begin{array}{l}32.9(31.0- \\
34.9)\end{array}$ \\
\hline \multirow[t]{2}{*}{ Triglycerides ${ }^{\mathrm{e}}$} & Normal & $\begin{array}{l}66.0(64.2- \\
67.8)\end{array}$ & $\begin{array}{l}67.8(65.7- \\
69.9)\end{array}$ & $\begin{array}{l}71.4(69.5- \\
73.2)\end{array}$ & $\begin{array}{l}74.5(72.5- \\
76.5)\end{array}$ \\
\hline & High & $\begin{array}{l}34.0(32.2- \\
35.8)\end{array}$ & $\begin{array}{l}32.2(30.1- \\
34.3)\end{array}$ & $\begin{array}{l}28.6(26.8- \\
30.5)\end{array}$ & $\begin{array}{l}25.5(23.5- \\
27.5)\end{array}$ \\
\hline
\end{tabular}




\begin{tabular}{|c|c|c|c|c|c|}
\hline & \multicolumn{3}{|c|}{ Enrollment $^{*}$} & \multicolumn{2}{|c|}{ First Repeated Measurement ${ }^{*}$} \\
\hline \multirow[t]{3}{*}{ Calcium $^{f}$} & Low & & & $\begin{array}{l}23.0(21.4- \\
24.7)\end{array}$ & $\begin{array}{l}27.9(25.9- \\
29.9)\end{array}$ \\
\hline & Normal & & & $\begin{array}{l}61.2(59.3- \\
63.1)\end{array}$ & $\begin{array}{l}57.6(55.5- \\
59.8)\end{array}$ \\
\hline & High & & & $\begin{array}{l}15.7(14.3- \\
17.1)\end{array}$ & $\begin{array}{l}14.5(12.9- \\
16.0)\end{array}$ \\
\hline \multirow[t]{4}{*}{ NAFLD } & Negative & $\begin{array}{l}58.8(56.8- \\
60.8)\end{array}$ & $\begin{array}{l}56.0(53.8- \\
58.2)\end{array}$ & $\begin{array}{l}54.2(52.2- \\
56.2)\end{array}$ & $\begin{array}{l}51.9(49.6- \\
54.2)\end{array}$ \\
\hline & Grade 1 & $\begin{array}{l}30.6(28.8- \\
32.5)\end{array}$ & $\begin{array}{l}30.9(28.8- \\
33.0)\end{array}$ & $\begin{array}{l}24.4(22.7- \\
26.1)\end{array}$ & $\begin{array}{l}29.5(27.5- \\
31.5)\end{array}$ \\
\hline & Grade 2 & $\begin{array}{l}9.1(7.9- \\
10.2)\end{array}$ & $\begin{array}{l}11.1(9.7- \\
12.5)\end{array}$ & $\begin{array}{l}16.2(14.7- \\
17.7)\end{array}$ & $\begin{array}{l}15.6(14.0- \\
17.2)\end{array}$ \\
\hline & Grade 3 & $1.5(1.0-2.0)$ & $2.0(1.4-2.6)$ & $5.2(4.3-6.1)$ & $3.0(2.0-4.0)$ \\
\hline \multirow[t]{2}{*}{ T2DM } & Negative & $\begin{array}{l}90.9(89.9- \\
92.0)\end{array}$ & $\begin{array}{l}83.6(82.1- \\
85.2)\end{array}$ & $\begin{array}{l}88.8(87.3- \\
89.3)\end{array}$ & $\begin{array}{l}79.1(77.0- \\
81.3)\end{array}$ \\
\hline & Positive & $\begin{array}{l}9.1(8.0- \\
10.1)\end{array}$ & $\begin{array}{l}16.4(14.8- \\
17.9)\end{array}$ & $\begin{array}{l}11.2(9.5- \\
12.7)\end{array}$ & $\begin{array}{l}20.9(18.7- \\
23.0)\end{array}$ \\
\hline \multirow[t]{4}{*}{ Anemia } & Negative & & & $\begin{array}{l}89.7(88.5- \\
90.8)\end{array}$ & $\begin{array}{l}80.9(79.3- \\
82.6)\end{array}$ \\
\hline & Normocytic & & & $4.0(3.2-4.7)$ & $7.1(6.1-8.2)$ \\
\hline & Microcytic & & & $6.2(5.3-7.0)$ & $\begin{array}{l}11.9(10.5- \\
13.2)\end{array}$ \\
\hline & Macrocytic & & & $0.2(0.0-0.3)$ & $0.0(0.0-0.0)$ \\
\hline \multicolumn{6}{|c|}{$\begin{array}{l}\text { BMI: body mass index, Cl: confidence interval, HDL-C: high-density lipoprotein cholesterol, LDL-C: low- } \\
\text { density lipoprotein cholesterol, n: count, T2DM: type } 2 \text { diabetes mellitus. }\end{array}$} \\
\hline \multicolumn{6}{|c|}{$\begin{array}{l}\text { a Underweight: }<18.5 \mathrm{~kg} / \mathrm{m}^{2} \text {, Normal: } 18.5-24.9 \mathrm{~kg} / \mathrm{m}^{2} \text {, Overweight: } 25-29.9 \mathrm{~kg} / \mathrm{m}^{2} \text {, Obese: } \geq 30 \\
\mathrm{~kg} / \mathrm{m}^{2}\end{array}$} \\
\hline \multicolumn{6}{|c|}{$\begin{array}{l}\text { b Desirable: }<200 \text { mg/dl, Borderline high: 200-239 mg/dl, High: 240-299 mg/dl, Very high: } \geq 300 \\
\text { mg/dl }\end{array}$} \\
\hline \multicolumn{6}{|c|}{$\begin{array}{l}\text { c Very low: }<70 \mathrm{mg} / \mathrm{dl} \text {, Low: } 70-99 \mathrm{mg} / \mathrm{dl} \text {, Borderline low: } 100-129 \mathrm{mg} / \mathrm{dl} \text {, Borderline high: } 130-159 \\
\text { mg/dl, High: } 160-189 \mathrm{mg} / \mathrm{dl} \text {, Very high: } \geq 190 \mathrm{mg} / \mathrm{dl}\end{array}$} \\
\hline \multicolumn{6}{|c|}{$\begin{array}{l}{ }^{\mathrm{d}} \text { Normal: } \geq 40 \mathrm{mg} / \mathrm{dl} \text { in men and } \geq 50 \mathrm{mg} / \mathrm{dl} \text { in women, Low: }<40 \mathrm{mg} / \mathrm{dl} \text { in men and }<50 \mathrm{mg} / \mathrm{dl} \text { in } \\
\text { women }\end{array}$} \\
\hline \multicolumn{6}{|c|}{ e Normal: $<150$ mg/dl, High: $\geq 150$ mg/dl } \\
\hline
\end{tabular}


f Low: $<8.8$ mg/dl, Normal: 8.8-10.7 mg/dl, High: >10.7 mg/dl

* Numbers represent "percentage (95\% confidence interval)".

\section{Causes of death}

As reported in Table 2, 160 participants, with the mean ( \pm standard deviation) age of $68.77( \pm 14.95)$ years, died during seven years of follow-up, mostly due to CVDs (except cerebrovascular accidents (CVA), 45 cases, $28.1 \%$ ), cancers ( 29 cases, $18.1 \%$ ), CVA ( 24 cases, $15.0 \%$ ), and motor vehicle accidents (10 cases, $6.3 \%)$. Also, 52 cases (32.5\%) died due to the other causes of death (including unknown causes).

Table 2

Count and causes of death in the Amol Cohort Study follow-up phase, 2011-2017

\begin{tabular}{|lllllll|}
\hline \multicolumn{7}{|c|}{ Cause of Death } \\
\hline Follow-up Year & CVD a & CVA & Cancers & MVA & Other $^{\text {b }}$ & Total $^{*}$ \\
\hline First (2011) & 4 & 2 & 3 & 2 & 5 & $16(10.0)$ \\
\hline Second (2012) & 5 & 2 & 2 & 1 & 4 & $14(8.7)$ \\
\hline Third (2013) & 5 & 1 & 5 & 1 & 11 & $23(14.4)$ \\
\hline Fourth (2014) & 10 & 9 & 6 & 1 & 9 & $35(21.9)$ \\
\hline Fifth (2015) & 4 & 1 & 6 & 2 & 7 & $20(12.5)$ \\
\hline Sixth (2016) & 15 & 7 & 4 & 1 & 12 & $39(24.4)$ \\
\hline Seventh (2017) & 2 & 2 & 3 & 2 & 4 & $13(8.1)$ \\
\hline Total ${ }^{*}$ & 45 (28.1) & 24 (15.0) & 29 (18.1) & $10(6.3)$ & $52(32.5)$ & $160(100.0)$ \\
\hline CVA: cerebrovascular accident, CVD: cardiovascular disease, MVA: motor vehicle accident. \\
\hline a Excluding cerebrovascular accidents.
\end{tabular}

\section{Discussion}


The primary phase of the AmolCS was conducted in 2009 with the main aim of evaluating obesity-related metabolic disorders, and CVDs. We investigated the prevalence of MetS, T2DM, and NAFLD in our sample population $[8,11,23]$. We also obtained the optimal cut-off points for homeostatic model assessment of insulin resistance (HOMA-IR) and various obesity measures in the diagnosis of T2DM, MetS, and NAFLD [24-33]. We compared various CVD risk assessment tools and evaluated the associations between NAFLD, MetS, and 10-year CVD risk as estimated by well-known international risk assessment tools [3437]. Additionally, we investigated the prevalence and risk factors of hepatitis $C$ in northern Iran [38].

Some aspects of the study design are novel. We have focused on NAFLD and other obesity-related metabolic disorders. Aiming to develop and validate LMIC-tailored risk assessment tools, we covered a unique population not represented in existing CVD cohorts. We adopted a multidisciplinary approach across levels of ministerial hierarchy to conduct the study and reduce cohort attrition.

The initial comprehensive assessment and subsequent follow-up of 5,394 participants in seven years with a multidisciplinary approach was the main strength of the AmolCS. The study involved data collection with frequent updates during seven years with a relatively high participant retention rate. There are several socioeconomic and cultural barriers impeding the coherence of participants in a longitudinal study [39]. In the AmolCS, we cooperated with the district health network to overcome these potential barriers. The health network universally covers the population regardless of socioeconomic status. Therefore, financial problems were not important barriers to the participation. Since all the personnel of the health network and the research center were trained local residents, we faced no cultural and communicational challenges (e.g. language). In addition to in-person visits, another factor supposed to yield a high retention rate in the cohort was a highly literate and well-educated population eagerly taking part in health surveillances. The sample population was also relatively stable with minimal migration.

Physical activity, tobacco smoking and other personal habits, diet, quality of life, stressful life events, biochemical profiles, liver ultrasonography, and ECG were evaluated in the enrollment and/or RM phases. We also cooperated with several specialists and sub-specialists to assess the participants, including those showing abnormalities in clinical and para-clinical evaluations. Obtained data encompassed demographic variables, medical conditions, lifestyle behaviors, and risk factors for the diseases of interest. The study outcomes offer an evidence base for further studies, and inform practice and policy regarding NCDs in Iran.

As with any cohort study, there are a few limitations related to the present study. The lack of data on electrocardiography, blood counts, glycated hemoglobin (HbA1C), C-reactive protein (CRP), thyroidstimulating hormone (TSH), triiodothyronine (T3), thyroxine (T4), blood urea nitrogen (BUN), creatinine, calcium, phosphorus, and 25-hydroxycholecalciferol (vitamin D) in the enrollment, and viral hepatitis markers in the first RM was the main drawback of the study, making the exclusion of prevalent diseases and the estimation of incident diseases difficult. For example, we could not use $\mathrm{HbA} 1 \mathrm{C}$ for estimation of T2DM incidence before 2017, but it would be feasible to estimate the incidence from 2017 to 2023, when the data is available. Recall bias and false reports are other potential sources of limitation in the study. To 
reduce information bias, we used approaches such as self-report and robust reviewing of medical documents.

In conclusion, we have focused on obesity-related metabolic disorders in a general population not represented in existing cohorts. A multidisciplinary approach for enrolling and following up helped to obviate barriers to participation. The AmolCS offers an evidence base for future studies, and informs policies regarding non-communicable diseases in Iran.

\section{Methods}

\section{Ethical considerations}

Following the principles of the Declaration of Helsinki, the study has been designed and conducted with formal approval of Research Ethics Committee of Iran University of Medical Sciences. All participants freely gave written informed consent prior to participation.

\section{Cohort catchment area}

The AmolCS has been conducted in the Haraz research center, covering general adult population of Amol and its rural surroundings since 2009. This research center is located in the Hefdah-e-Shahrivar Hospital, a non-academic district hospital in Amol city. Amol is one of the most populated cities of Mazandaran, a Caspian Sea coastal province in northern Iran (Fig. 2). The city has a Mediterranean climate with relative hot summers and cool, humid winters. The main agricultural export product and main food of the population of Amol is high-quality rice. Based on the last national census, Amol district has 401,639 residents (202,502 men and 199,137 women) in 133,034 households. Of this population, 246,355 (61.3\%, 123,158 men and 123,197 women) live in 81,433 urban households and 155,284 (38.7\%, 79,344 men and 75,940 women) live in 51,601 rural households [40]. Notably, Mazandaran province has the highest literacy rate $(97.6 \%)$ in Iran according to the census [40].

\section{Recruitment and enrollment}

Assuming that the expected annual incidence of NAFLD is $10 \%$ [41], and assuming the precision of $1 \%$, type 1 error of $5 \%$, and expected drop-out rate of $50 \%$, the following formula estimated that a total of nearly 7,000 people should be recruited:

$$
N=Z_{1-\alpha / 2}^{2}[p(1-p)] / \delta^{2} ; \alpha=0.05, p=0.1, \delta=0.01
$$

We held meetings with the head of district health network and stated the objectives of the study to gain the cooperation of rural and urban health centers and their respectively affiliated health houses and health posts (Fig. 3). Each rural health center supervises several health houses where Behvarzes work. A Behvarz is an employee certified to provide free universal primary healthcare packages, such as vaccination, screening, perinatal cares, and environmental health services (e.g., water sanitation), for all 
registered inhabitants. Behvarzes are selected from indigenous candidates who merit the educational, practical, and ethical prerequisites. They are acquainted with local culture and language, and can easily communicate with the locals. We held meetings with Behvarzes, explained the study objectives, and provided a brief tutorial on how to invite the eligible individuals to the research center. We continuously communicated with Behvarzes to check the progress and update participants' information. In urban areas, we faced fewer restrictions because the research center was located in the city, and thus, access to the research center and to the eligible participant was relatively easier. However, we were in continuous contact with staff of health posts to invite the residents to the research center.

The primary data (particularly, demographics) of residents in rural and urban areas are documented in household records kept in related health houses and posts. Therefore, we developed a sampling frame based on the data from health houses and health posts in rural and urban areas, respectively. Individuals aged 10-90 years were considered eligible for participation in the study. We divided the population into 16 strata based on sex and age groups $(10-19,20-29,30-39,40-49,50-59,60-69,70-79$, and $80-90$ years). Participants were randomly selected from each stratum according to its proportional size. We invited 7,104 individuals and $88.6 \%$ agreed to participate in the cohort. Excluding children (younger than 18 years), sojourners, unwilling individuals, and pregnant women, we enrolled 5,799 eligible residents from the general population of Amol (Fig. 1).

The enrollment phase was conducted in approximately 18 months (2009-2010). Eighteen personnel, with academic degree in nursing, carried out interviews, measurements, sample collection and preparation, and data entry. These personnel, who were familiar with both Persian and local languages, were theoretically and practically trained during a 2-week course on the study objectives and protocols.

The enrollees arriving at the research center were informed of the purpose and workflow of the study. We obtained written informed consents (in Persian), stating invasive procedures, confidentiality of disclosing information, and the unconditional right to withdraw at any time, from those willing to participate. A unique code was assigned to each participant upon registration to make the data and samples anonymized.

\section{Blood sampling}

A day before the registration, the participants were asked to fast for 12 hours before attending the research center in the next morning. Before taking blood, all tubes were labeled appropriately. After registration and following standard protocols, $20 \mathrm{~mL}$ of fasting antecubital venous blood sample was obtained from each participant. Half of the blood sample was transferred to a serum separator tube and kept at room temperature for 30 minutes to allow for clotting. These samples were immediately centrifuged at 3000 revolutions per minute (RPM) for 10 minutes. Then, serum was separated using clean pipette technique. An appropriate amount of serum was used for biochemical assessments; and the remaining serum was aliquoted into labeled $500 \mu \mathrm{L}$ cryotubes (Eppendorf Intl., Hamburg, Germany) and stored at $-80^{\circ} \mathrm{C}$. The other half of the blood sample was used for plasma separation from an ethylenediamine-tetraacetic acid-containing collection tube and centrifuged at 3000 RPM for 10 minutes. Using 
clean pipette technique, $1.0 \mathrm{~mL}$ of plasma was separated, aliquoted into labeled $1.5 \mathrm{~mL}$ cryotubes, and stored at $-80^{\circ} \mathrm{C}$.

\section{Anthropometry}

Anthropometric indices were measured after sample collection, while the participant was still fasting. The participant was then provided with a snack. Weight (in $\mathrm{kg}$ ) was measured using a digital scale (seca GmbH \& Co.KG, Hamburg, Germany) after the participant removed her/his shoes and excess cloths. It was recorded as rounded to the nearest $0.1 \mathrm{~kg}$. Also, height (rounded to the nearest $0.5 \mathrm{~cm}$ ) of barefoot participants was measured in an upright position with their heels, buttocks, and scapulae pressed up against a wall, using a wall-mounted manual stadiometer (seca GmbH \& Co.KG, Hamburg, Germany). The participant weight was divided by the square of the height $\left(\mathrm{kg} / \mathrm{m}^{2}\right)$ to calculate the BMI.

Using a plastic tape measure, waist circumference (rounded to the nearest $0.1 \mathrm{~cm}$ ) was measured in a horizontal plane at the midpoint between the lowest costal ridge and the upper border of iliac crest, in standing posture and at the end of a gentle expiration. While standing with the legs close together, the largest circumference between waist and knee was measured using the tape, rounded to the nearest 0.1 $\mathrm{cm}$, and recorded as the participant's hip circumference (in $\mathrm{cm}$ ). Waist circumference was divided by hip circumference to calculate the waist-to-hip ratio.

\section{Questionnaires}

All questionnaires were checked for completeness by the data supervisor. Data on sex, age, marital status, educational level, occupation, and residency status (urban and rural) were collected upon registration. The interviewers investigated medical history of the participants and their family members, particularly for CVDs (hypertension, ischemic heart disease, heart failure, CVA, and other CVDs), T2DM, dyslipidemia, asthma, obstetrics history, gynecological disorders, malignancies, hospitalization, surgical procedures, chemotherapy or radiotherapy, transfusion, and cause-specific death. They also investigated participant's drug history, particularly anti-hypertensive, anti-coagulant, anti-hyperglycemic, anti-lipemic, and anti-asthmatic medications.

Personal habits (tobacco smoking, alcohol consumption, and narcotics abuse) were assessed qualitatively in the enrollment phase. Severity and duration of physical activity were evaluated using the international physical activity questionnaire. Interviewers also completed 12-item general health questionnaire and 12-item short form health survey questionnaire. In addition, gastroesophageal reflux disease questionnaire was completed for each participant.

\section{Clinical evaluations}

Blood pressure (in $\mathrm{mmHg}$ ) was measured twice using a fitted sphygmomanometer cuff (Riester $\mathrm{GmbH}$, Jungingen, Germany) while the participant was in a sitting position, after at least five minutes of inactivity in a quiet room. Systolic and diastolic blood pressures were determined based on Korotkoff sounds. The average of two measured values was considered as the participant's blood pressure. 
A single expert radiologist performed hepatobiliary ultrasonography using a 3-5 $\mathrm{MHz}$ transducer (Esaote $\mathrm{SpA}$, Genova, Italy). Sagittal, longitudinal, lateral, and intercostal views of the liver parenchyma and biliary system were obtained and all findings, including hepatomegaly, steatosis, cirrhosis, cholelithiasis, cysts, polyps, calcifications, hemangioma, and space-occupying lesions were recorded.

\section{Laboratory assessments}

We enzymatically assessed serum samples using an Auto-Analyzer BS200 (Mindray, Shenzhen, China) and diagnostic kits (Pars Azmoon Co., Tehran, Iran) for fasting blood sugar, insulin, total cholesterol, highdensity lipoprotein cholesterol, low-density lipoprotein cholesterol, triglycerides, alanine aminotransferase, aspartate aminotransferase, alkaline phosphatase, and y-glutamyl transpeptidase. Enzyme-linked immunosorbent assay (ELISA) kits (Pishtaz Teb Co., Tehran, Iran) were used for evaluating hepatitis B surface antigen, hepatitis $B$ surface antibody, hepatitis $B$ core antibody, and hepatitis $C$ virus antibody in the enrollment phase. Then, 10 percent of the blood samples were re-evaluated by the Iranian National Reference Laboratory. The coefficients of variation ranged from $1.7-3.8 \%$ for all laboratory values. All test results were recorded and a copy was provided to the participant.

\section{Follow-up}

After the enrollment, the participants have been and will be actively followed up annually by phone for 20 years. In the case of not receiving an answer from a participant following three phone calls, the research team contacted the related health house or health post staff to establish reasons, if any (withdrawal, emigration, or death). To minimize the cohort attrition and participant withdrawal, the team offered reassurances and more study details whenever participants required. If the participant was still in the catchment area, i.e., lived in the same postal address given in the enrollment phase or moved to another covered address, the team would contact and invite the participant to a face-to-face meeting to alleviate possible concerns and provide needed information.

During active follow-ups, questionnaires were and will be completed regarding the occurrence of death and incidence of medical events, hospitalizations, or diagnostic and therapeutic procedures, particularly those related to the outcomes of interest, such as angiography, coronary angioplasty, or cardiac surgery. In case of death or incidence of the outcomes of interest, the participant or her/his family members were asked to bring all relevant medical documents, such as hospital records and death certificate, to the research center. If participants or their family members could not come to the center, the team would refer to hospital or the participant's residence to collect and review copies of pertinent documents, and make record of the data. A trained internist reviewed the medical documents and confirmed the diagnosis of disease, and the date and cause of death.

Passive follow-up was also conducted through self-reports. At the time of enrollment, the participants and their family members were provided with a contact number to inform the research team in the event of death, hospitalization, or development of major medical events, as soon as possible. After receiving selfreports, the team referred to hospitals or participant's residence, collected and reviewed the medical documents, confirmed the outcomes, and recorded the data. 


\section{Endpoints}

The endpoints of the study are death, withdrawal, and migration of participants.

\section{Repeated measurements}

After seven years, we resumed meetings with the head of district health network to gain their cooperation in the first RM phase (2016-2017). Again, Behvarzes and staff of health posts provided assistance in actively inviting the participants to the research center. The research team communicated with the participants regarding the main goals of the RM phase and invited them by phone call to refer to the research center. Currently, two more RM phases with 7-year intervals are considered for a comprehensive evaluation of participants in 2023 and 2030.

In the first RM, data on sex, age, marital status, educational level, and residency status were collected again. The interviewers re-investigated medical history, drug history, family history, and personal habits of the participants. Unlike the enrollment phase, tobacco smoking and alcohol consumption were assessed quantitatively in the first RM. The same questionnaires of physical activity and quality of life were completed again in the first RM. A food frequency questionnaire and the Holmes-Rahe stress questionnaire were also added in the first RM.

Protocols for measurement of weight, height, and circumferences of waist and hip were the same as in the enrollment phase. In addition, arm, wrist, and neck circumferences were measured in the first RM. Arm circumference (rounded to the nearest $0.1 \mathrm{~cm}$ ) was measured using a plastic tape measure around the anatomically positioned non-dominant upper arm at the midpoint between the acromion and the olecranon and perpendicular to the longitudinal axis of the arm. Wrist circumference (rounded to the nearest $0.1 \mathrm{~cm}$ ) was measured using the tape positioned over radial styloid process and ulnar styloid process of participant's dominant hand. Neck circumference (rounded to the nearest $0.1 \mathrm{~cm}$ ) was measured in the midway of the neck, between mid-cervical spine and mid anterior neck, using the plastic tape while the participant was standing and looking straight ahead with shoulders down, but not hunched. Trapezius muscles were not involved in the measurement. In case of a laryngeal prominence, it was measured just below the thyroid cartilage.

Protocols for blood pressure measurement and hepatobiliary ultrasonography were the same as in the enrollment phase. A standard 12-lead electrocardiogram (ECG) was also provided for each participant in the first RM. Duration of PR interval, amplitude and duration of QRS complex, ST segment deviations, and duration and abnormalities of T wave, if any, were documented. In addition to an automated ECG interpretation, two internists evaluated every ECG. All suspected or abnormal cases were referred to and confirmed by an expert cardiologist.

The blood samples were collected and prepared following the same protocols of the enrollment phase. In addition to the same biochemical profiles assessed in the enrollment, we worked with the Auto-Analyzer and diagnostic kits to evaluate serum concentrations of HbA1C, uric acid, BUN, creatinine, CRP, TSH, T3, 
T4, vitamin D, calcium, and phosphorus in the first RM. Tissue transglutaminase antibody was assessed with ELISA kits in the first RM. We also used an automated blood cell counter (Sysmex K1000, Hamburg, Germany) for complete and differential blood counts, such as hemoglobin concentration, and red blood cell count, volume and morphology. All test results were recorded and a copy was provided to the participant.

\section{Declarations}

\section{Data availability:}

The datasets generated and/or analyzed during the current study are not publicly available due to legal restrictions, but are available from the corresponding author on reasonable request.

\section{Acknowledgements:}

This study was financially supported by Gastrointestinal and Liver Diseases Research Center of Iran University of Medical Sciences.

\section{Author contributions:}

NM and FZ conceptualized and designed the study. FZ administrated and supervised the project. NM, FR, $H P, G H A$, and DP provided methodological consults. MM, HA, HK, RS, BR, MML, MK, MA, MN, AHF, ZK, MRS, BA, FST, EG, SHH, and MHKN investigated and collected the data. MM, HA, RS, MK, AHF, and SHH validated the data. NM and FR analyzed the data and drafted the manuscript. All authors critically revised and approved the final manuscript. FZ is the guarantor and takes the responsibility of the paper as a whole.

\section{Additional Information}

\section{Competing interests:}

Authors declare no competing interests.

\section{References}

1. Global Burden of Disease Diseases and Injuries Collaborators. Global burden of 369 diseases and injuries in 204 countries and territories, 1990-2019: a systematic analysis for the Global Burden of Disease Study 2019. Lancet 396, 1204-1222 (2020).

2. World Health Organization. Global status report on noncommunicable diseases 2014. (WHO Press, Geneva, Switzerland, 2014).

3. Eghtesad, S. et al. The PERSIAN cohort: providing the evidence needed for healthcare reform. Archives of Iranian medicine 20, 691-695 (2017). 
4. Global Burden of Disease Diet Collaborators. Health effects of dietary risks in 195 countries, 19902017: a systematic analysis for the Global Burden of Disease Study 2017. Lancet 393, 1958-1972 (2019).

5. Ng, M. et al. Global, regional, and national prevalence of overweight and obesity in children and adults during 1980-2013: a systematic analysis for the Global Burden of Disease Study 2013. Lancet 384, 766-781 (2014).

6. Apovian, C. M. Obesity: definition, comorbidities, causes, and burden. The American journal of managed care 22, s176-185 (2016).

7. Prospective Studies Collaboration et al. Body-mass index and cause-specific mortality in 900000 adults: collaborative analyses of 57 prospective studies. Lancet 373, 1083-1096 (2009).

8. Amirkalali, B. et al. Prevalence of non-alcoholic fatty liver disease and its predictors in north of Iran. Iranian journal of public health 43, 1275-1283 (2014).

9. Farrell, G. C., Wong, V. W. \& Chitturi, S. NAFLD in Asia--as common and important as in the West. Nat Rev Gastroenterol Hepatol 10, 307-318 (2013).

10. Sanyal, A. J. NASH: a global health problem. Hepatol Res 41, 670-674 (2011).

11. Rabiee, B. et al. The prevalence of non-alcoholic fatty liver disease and diabetes mellitus in an Iranian population. Middle East journal of digestive diseases 9, 86-93 (2017).

12. Heidenreich, P. A. et al. Forecasting the future of cardiovascular disease in the United States: a policy statement from the American Heart Association. Circulation 123, 933-944 (2011).

13. Kochanek, K. D., Xu, J., Murphy, S. L., Minino, A. M. \& Kung, H. C. Deaths: final data for 2009. National vital statistics reports : from the Centers for Disease Control and Prevention, National Center for Health Statistics, National Vital Statistics System 60, 1-116 (2011).

14. Nabipour, I. et al. The metabolic syndrome and nonfatal ischemic heart disease; a population-based study. International journal of cardiology 118, 48-53 (2007).

15. Poustchi, H. et al. Prospective epidemiological research studies in Iran (the PERSIAN cohort study): rationale, objectives, and design. American journal of epidemiology 187, 647-655 (2018).

16. Naghavi, M. et al. Health transition in Iran toward chronic diseases based on results of Global Burden of Disease 2010. Archives of Iranian medicine 17, 321-335 (2014).

17. Lozano, R. et al. Global and regional mortality from 235 causes of death for 20 age groups in 1990 and 2010: a systematic analysis for the Global Burden of Disease Study 2010. Lancet 380, 20952128 (2013).

18. Anstee, Q. M., Targher, G. \& Day, C. P. Progression of NAFLD to diabetes mellitus, cardiovascular disease or cirrhosis. Nat Rev Gastroenterol Hepatol 10, 330-344 (2013).

19. Bhatia, L. S., Curzen, N. P., Calder, P. C. \& Byrne, C. D. Non-alcoholic fatty liver disease: a new and important cardiovascular risk factor? Eur Heart J 33, 1190-1200 (2012).

20. Maurantonio, M., Ballestri, S., Odoardi, M. R., Lonardo, A. \& Loria, P. Treatment of atherogenic liver based on the pathogenesis of nonalcoholic fatty liver disease: a novel approach to reduce 
cardiovascular risk? Arch Med Res 42, 337-353 (2011).

21. Targher, G., Day, C. P. \& Bonora, E. Risk of cardiovascular disease in patients with nonalcoholic fatty liver disease. N Engl J Med 363, 1341-1350 (2010).

22. Malekzadeh, A., Michels, K., Wolfman, C., Anand, N. \& Sturke, R. Strengthening research capacity in LMICs to address the global NCD burden. Glob Health Action 13, 1846904 (2020).

23. Ostovaneh, M. R. et al. Prevalence of metabolic syndrome in Amol and Zahedan, Iran: a population based study. Archives of Iranian medicine 17, 477-482 (2014).

24. Motamed, N. et al. Optimal cutoff points for HOMA-IR and QUICKI in the diagnosis of metabolic syndrome and non-alcoholic fatty liver disease: a population based study. Journal of diabetes and its complications 30, 269-274 (2016).

25. Motamed, N. et al. Discriminatory ability of visceral diposity index (VAI) in diagnosis of metabolic syndrome: a population based study. Experimental and clinical endocrinology \& diabetes : official journal, German Society of Endocrinology [and] German Diabetes Association 125, 202-207 (2017).

26. Motamed, N. et al. Conicity index and waist-to-hip ratio are superior obesity indices in predicting 10year cardiovascular risk among men and women. Clinical cardiology 38, 527-534 (2015).

27. Motamed, N. et al. Body roundness index and waist-to-height ratio are strongly associated with nonalcoholic fatty liver disease: a population-based study. Hepatitis monthly 16, e39575 (2016).

28. Motamed, N. et al. The best obesity indices to discriminate type 2 diabetes nellitus. Metabolic syndrome and related disorders 14, 249-253 (2016).

29. Motamed, N., Razmjou, S., Hemmasi, G., Maadi, M. \& Zamani, F. Lipid accumulation product and metabolic syndrome: a population-based study in northern Iran, Amol. Journal of endocrinological investigation 39, 375-382 (2016).

30. Motamed, N. et al. Fatty liver index vs waist circumference for predicting non-alcoholic fatty liver disease. World journal of gastroenterology 22, 3023-3030 (2016).

31. Motamed, N. et al. The six obesity indices, which one is more compatible with metabolic syndrome? a population based study. Diabetes \& metabolic syndrome 11, 173-177 (2017).

32. Motamed, N. et al. The best obesity indices to use in a single factor model indicating metabolic syndrome: a population based study. Archives of Iranian medicine 19, 110-115 (2016).

33. Ostovaneh, M. R. et al. Nonalcoholic fatty liver: the association with metabolic abnormalities, body mass index and central obesity-a population-based study. Metabolic syndrome and related disorders 13, 304-311 (2015).

34. Motamed, N. et al. The 10-year absolute risk of cardiovascular (CV) events in northern Iran: a population based study. Materia socio-medica 27, 158-162 (2015).

35. Motamed, N. et al. Comparison of cardiovascular risk assessment tools and their guidelines in evaluation of 10-year CVD risk and preventive recommendations: a population based study. International journal of cardiology 228, 52-57 (2017). 
36. Motamed, N. et al. Non-alcoholic fatty liver disease (NAFLD) and 10-year risk of cardiovascular diseases. Clinics and research in hepatology and gastroenterology 41, 31-38 (2017).

37. Motamed, N. et al. Metabolic syndrome and cardiovascular risk assessment tools' estimations of 10year cardiovascular risk: a population-based study. Acta cardiologica, 1-8 (2017).

38. Zamani, F. et al. Prevalence and risk factors of hepatitis $C$ virus infection in Amol city, north of Iran: a population-based study (2008-2011). Hepatitis monthly 13, e13313 (2013).

39. Abshire, M. et al. Participant retention practices in longitudinal clinical research studies with high retention rates. BMC Med Res Methodo/ 17, 30 (2017).

40. Statistical Center of Iran. 2016 National population and housing census. Available at https://www.amar.org.ir/english/Population-and-Housing-Censuses/Census-2016-General-Results (2016).

41. Ong, J. P., Pitts, A. \& Younossi, Z. M. Increased overall mortality and liver-related mortality in nonalcoholic fatty liver disease. J Hepatol 49, 608-612 (2008).

\section{Figures}




\section{Disagreement:}

808 invitees did not agree to participate in the cohort.

Exclusion:

153 pregnant women;

344 younger than 18 years.

7-year Attrition:

46 migrated;

359 (7 pregnant) withdrew.

7,104 residents

aged $10-90$ years were

randomly invited to the cohort

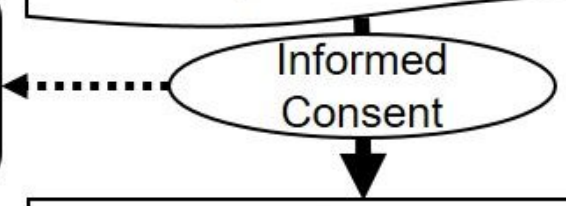

6,296 subjects agreed to participate in the cohort

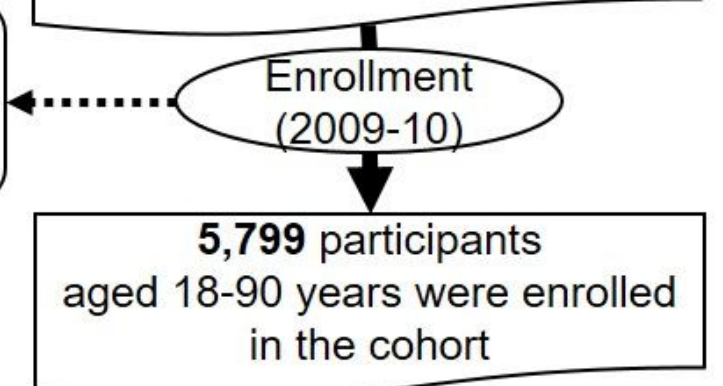
in the cohort

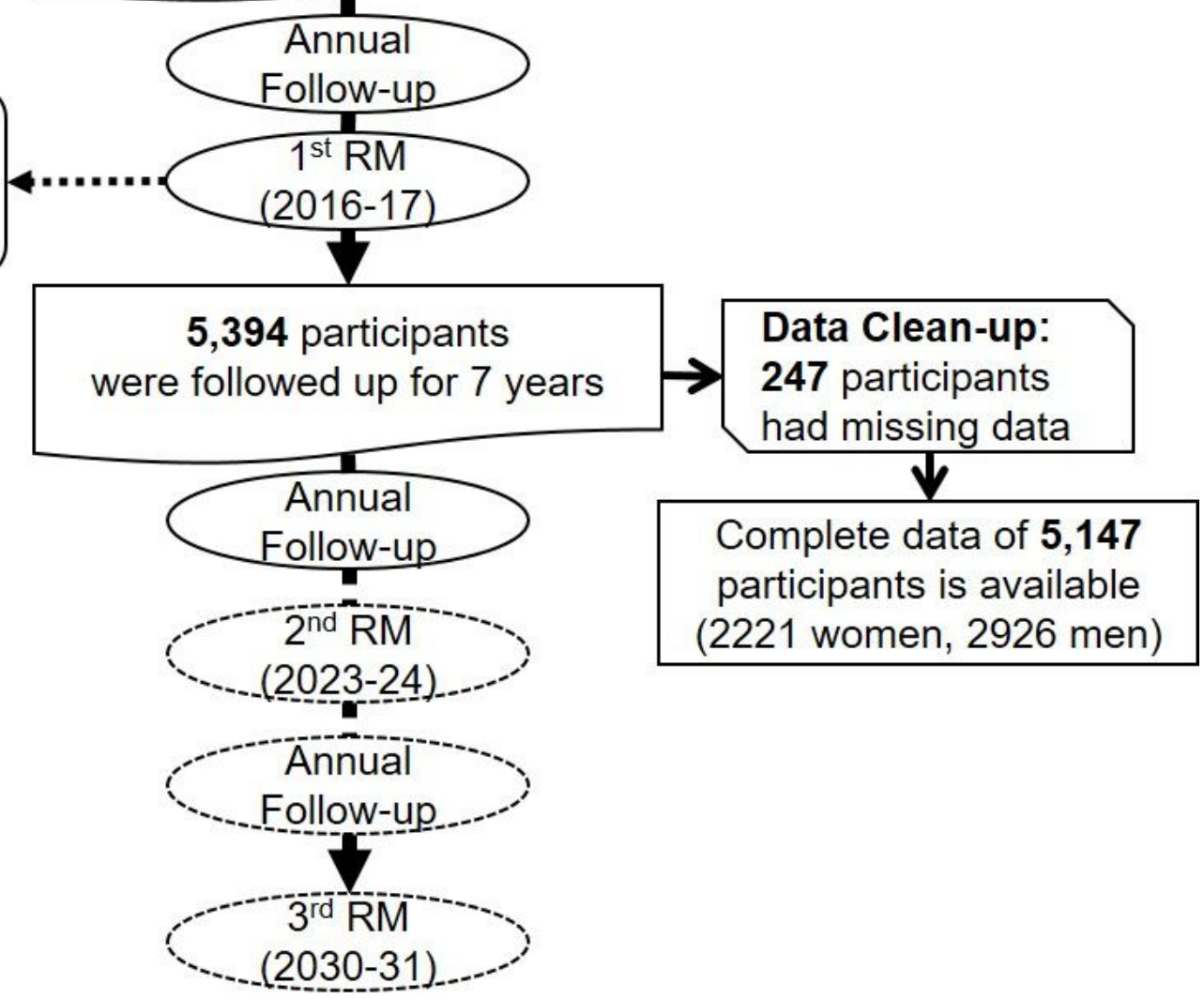

\section{Figure 1}

Schematic flowchart of the Amol Cohort Study (RM: repeated measurement) 


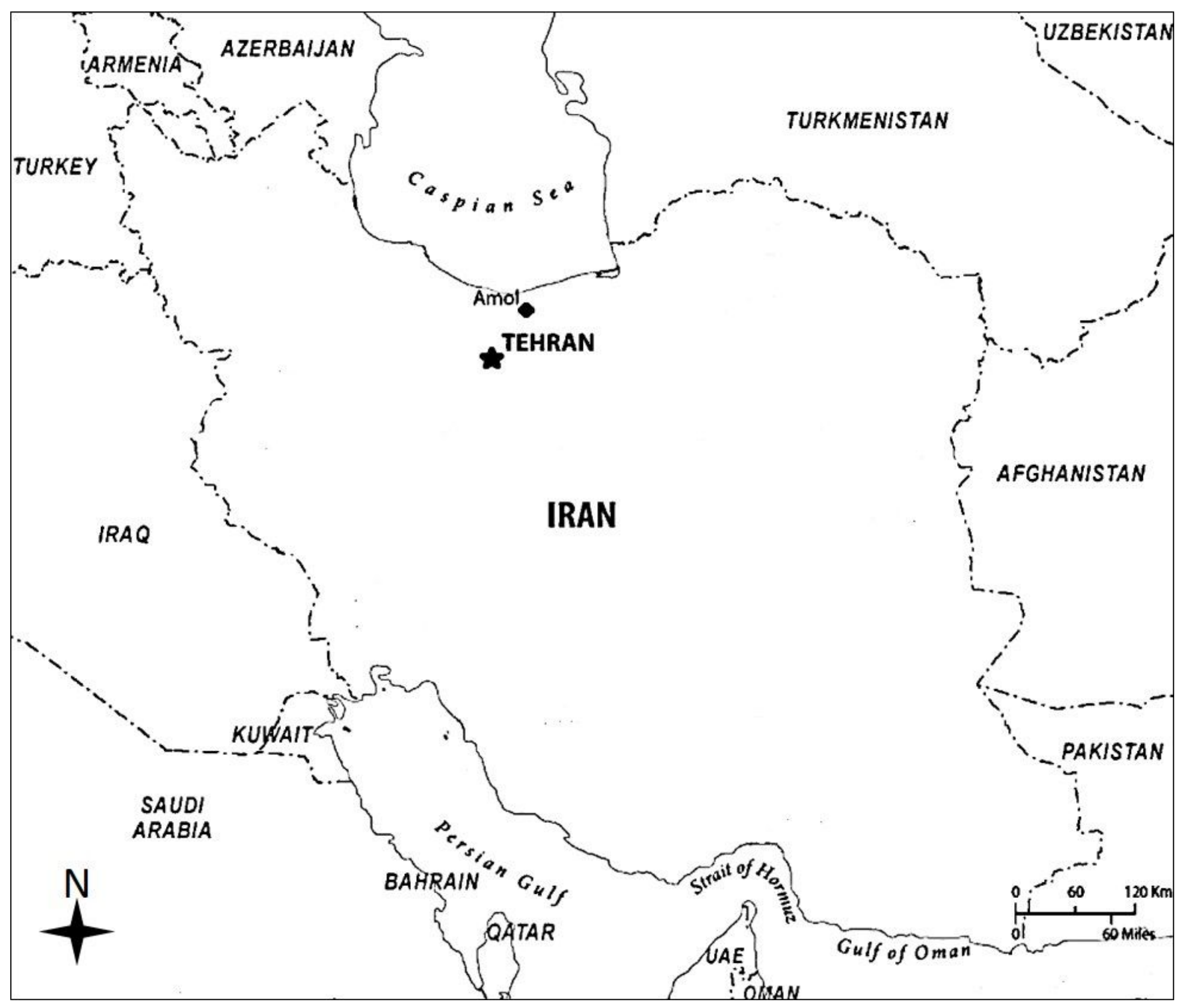

Figure 2

Geographic location of Amol city, the catchment area of the Amol Cohort Study, in northern Iran 


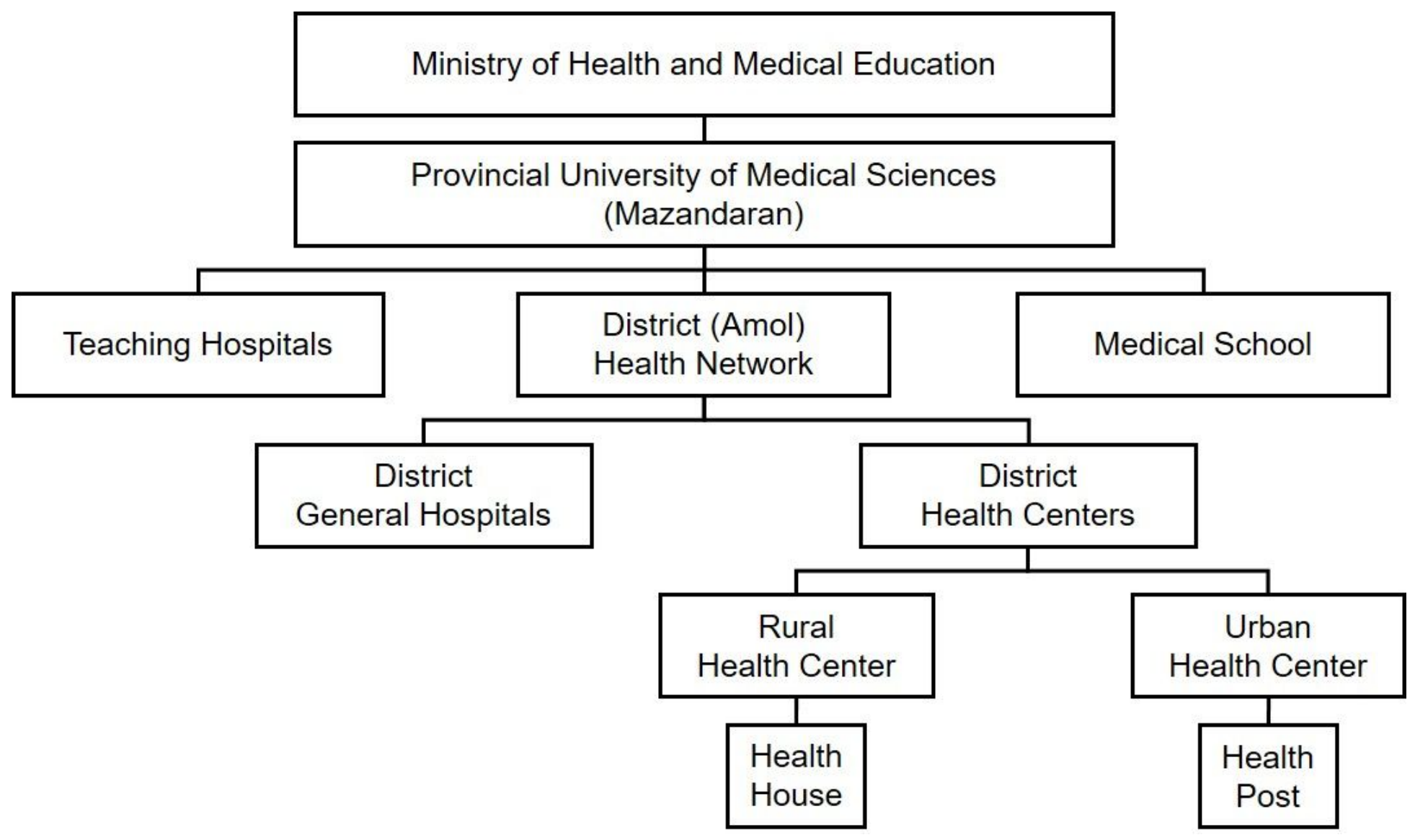

Figure 3

The structure of healthcare network in Iran 